
\title{
The Factors Affecting Small Bowel Volume in the Pelvis of Patients Receiving Radiotherapy for Rectal
}

\section{Cancer}

\author{
Junliang Liu \\ Department of Radiation Oncology, Cancer Care Manitoba, Winnipeg, MB, Canada
}

*Corresponding author: Junliang Liu, Department of Radiation Oncology, Cancer Care Manitoba, R3E 0V9, Winnipeg, MB, Canada, Tel: +1 2047871927; Fax: +1 2047860194; E-mail: junliang.liu@cancercare.mb.ca

Received Date: 09 May, 2017; Accepted Date: 12 July, 2017; Published Date: 28 July, 2017

\begin{abstract}
Purpose: Radiation (RT)-Induced Gastrointestinal (GI) toxicities are associated the small bowel volume irradiated and the dosage received. However, rectal cancer patients treated with neoadjuvant Chemoradiotherapy (CRT) experience less GI toxicities compared to adjuvant chemoradiotherapy. The purpose of this study was to explore the factors which are associated with the small bowel volume in the pelvic radiation fields.
\end{abstract}

Materials and methods: Patients with rectal cancer who had pre- or post-surgery CRT and were treated by a single radiation oncologist were included. All patients were treated with 3-D conformal radiotherapy. The volume of the organs was determined from planning CT scans. Acute toxicity was graded using Radiation Therapy Oncology Group (RTOG) Common Toxicity Criteria. Acute GI toxicity and its associated determinants such as age, bladder volume, gender, Body Mass Index (BMI), and type of surgery were documented.

Results: A total of 119 patients ( 71 males, 48 females) 35 to 88 years of age were recruited. Sixty one out of 119 patients had pre-surgery RT or CRT and 58 patients had post-surgery therapy. Single predictors for greater irradiated small bowel volume were post-surgery treatment, female sex, smaller bladder volume and older age. The small bowel volume tended to increase with lower BMI and abdominoperineal resection. Multivariate analysis indicated that post-surgery treatment, being a female, and having a smaller bladder volume were predictors of greater irradiated volume of the small bowel.

Conclusion: Factors such as pelvic surgery, being female, flat bladder, and older age are associated with increased small bowel volumes in pelvis. These would increase the irradiated small bowel volumes in patients receiving radiotherapy for rectal cancer. Therefore, giving radiotherapy before the surgery or using technical such as IMRT or Rapid Arc to avoid or reduce the small bowel volumes being irradiated is warranted.

\section{Keywords}

Chemo-Radiotherapy; Dose-Volume Histogram; Multivariate Analysis; Rectal Cancer; Small Bowel

\section{Introduction}

Neoadjuvant chemoradiotherapy was shown to improve local control, and to decrease toxicities as compared to adjuvant chemoradiotherapy $[1,2]$ though both neoadjuvant and adjuvant chemoradiotherapy are associated with improving overall survival as well as local control in patients with locally advanced rectal cancer [3-6] compared to surgery alone. Both neoadjuvant and adjuvant chemoradiotherapy have been associated with acute diarrhea [5-7] but it has been demonstrated that neoadjuvant treatment is superior to adjuvant treatment with respect to the decreased bowel toxicities [5]. Although diarrhea can be caused by chemotherapy [8] surgery [9] or radiotherapy [10] small bowel toxicity resulting from irradiation has been shown as part of the causes of acute diarrhea during the treatment [11]. However, there are no published data on the factors that may affect the small bowel volume irradiated, and this study was conducted to analyze the factors which are associated with the small bowel volume in the pelvis.

\section{Methods and Materials}

\section{Patient eligibility}

Eligibility criteria included consecutive patients with Stage I and Stage IV rectal cancers who received either neoadjuvant chemoradiotherapy or neoadjuvant radiotherapy alone or adjuvant 
Citation: Liu J (2017) The Factors Affecting Small Bowel Volume in the Pelvis of Patients Receiving Radiotherapy for Rectal Cancer. J Clin Case Rep Case Stud 2017: 1-5. DOI : https://doi.org/10.29199/2637-9309/CCCS-101011.

chemoradiotherapy in a single institute during the period of 2005 to 2010 .

\section{Study design}

The patients were immobilized in supine position. The small bowel contrast (telebrix 38 Oral, tyco/healthcare) was given orally 1 hour before treatment planning computed tomography scan. Transverse images at $3 \mathrm{~mm}$ intervals were obtained. The volume of small bowel was outlined by contouring the small bowel loops $1 \mathrm{~cm}$ above the superior edge of the Planning Target Volume (PTV) and the absolute volume quantified ( $\mathrm{cm} 3)$ using Eclipse or Pinnacle planning software (Figures 1 and 2). The volumetric assessment of small bowel dose was performed based on the actual Dose Volume Histogram (DVH) of the three dimensional conformal radiotherapy treatment planning for each patient prospectively. The majority of patients received three-fields (posterior-anterior and opposed lateral fields). Most of the patients received 50.4 Gy in 28 fractions. Acute diarrhea was graded per RTOG Criteria [12].

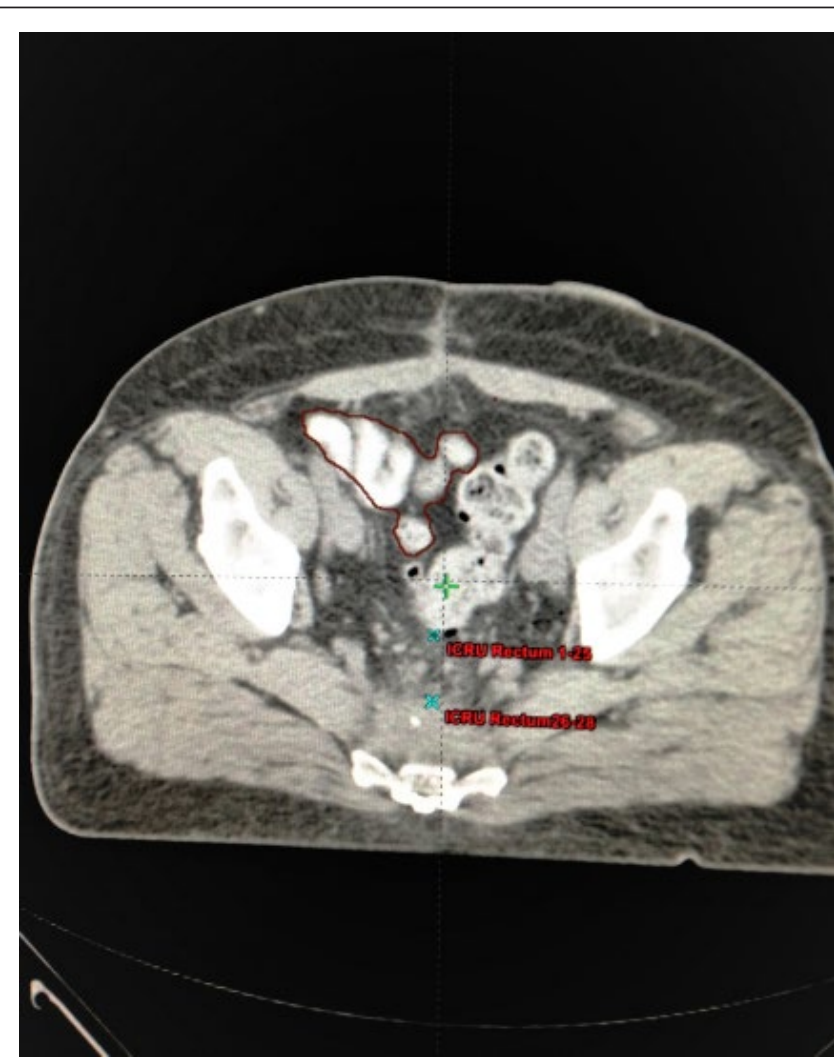

Figure 1: Radiotherapy simulation $\mathrm{CT}$ scan of a 67 year old man with a resected upper rectal cancer. The contrast-filled small bowel loops are contoured.

\section{Statistical methods}

Patients were divided into neoadjuvant treatment (including four patients who received radiotherapy alone) and adjuvant groups. Data were analyzed using Chi-Square, Wilcoxan Rank test, and linear regression. A P-value of 0.05 or less was considered statistically significant.

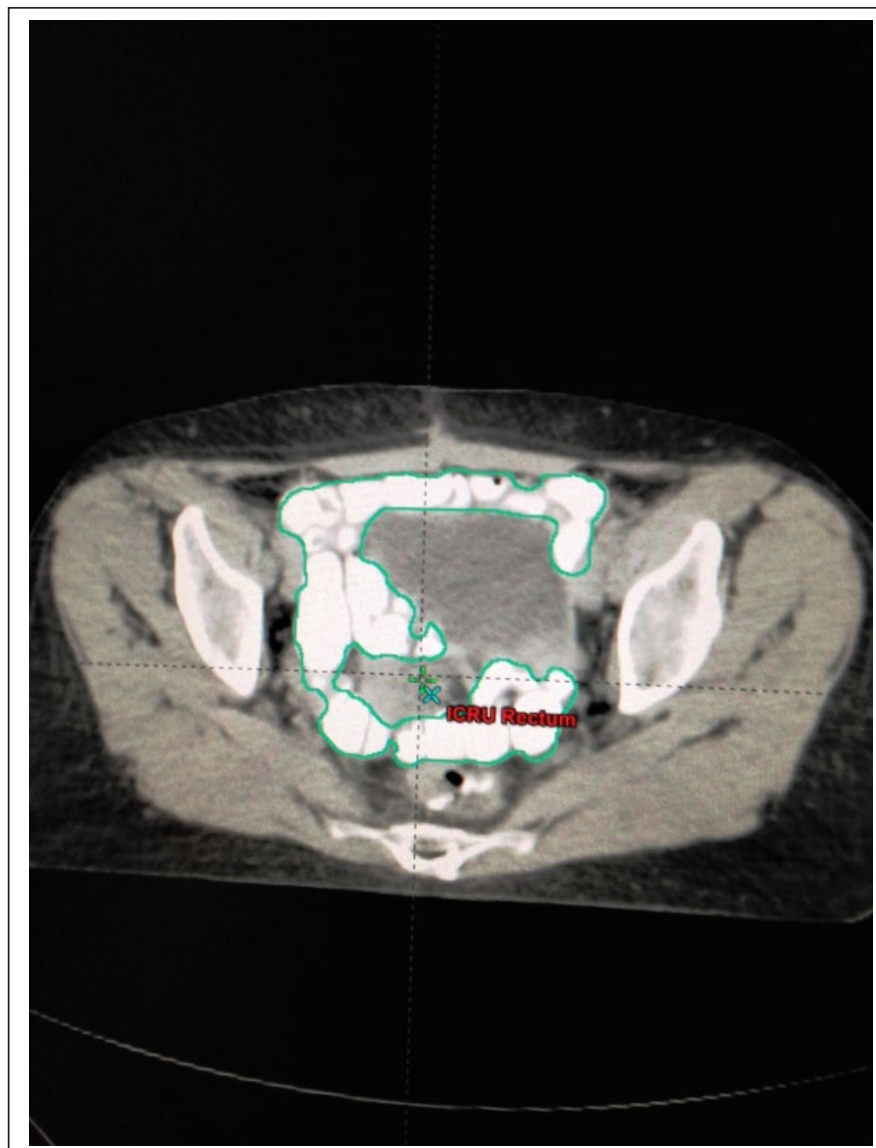

Figure 2: Radiotherapy simulation CT scan of a 66 year old woman with a resected upper rectal cancer. The contrast-filled small bowel loops are contoured.

\section{Results}

A total of 119 patients ( 71 males, 48 females) 35 to 88 years of age were treated by a single radiation oncologist. Sixty one patients had neo-adjuvant and 58 had adjuvant radiotherapy. One hundred and six of patients had concomitant chemotherapy (Table 1). The acute diarrhea was grade 1 in 42 patients $(35.3 \%)$, grade 2 in 12 patients $(10.1 \%)$, grade 3 in 7 patients $(5.9 \%)$, and grade 4 in 8 patients $(6.7 \%)$. The volume of the small bowel in the radiation fields was significantly increased in patients receiving adjuvant treatment (Table 2). Interestingly, small bowel volume in the pelvis was higher in female patients than in male patients (Table 3). Univariate analysis showed that adjuvant RT, female gender, smaller bladder volume, and older age were significant determinants related to increased small bowel volume in the pelvis while there was a trend for increased small bowel volume in the pelvis for patients with lower BMI (Table 4). Multivariate analysis confirmed adjuvant RT, female gender, and smaller bladder volume were statistically significant factors affecting the pelvic small bowel volume (Table 5). There was no significant difference of Planning Target Volume (PTV) between patient groups (neo-adjuvant versus adjuvant or female versus male) (Table 6). 
Citation: Liu J (2017) The Factors Affecting Small Bowel Volume in the Pelvis of Patients Receiving Radiotherapy for Rectal Cancer. J Clin Case Rep Case Stud 2017: 1-5.

\begin{tabular}{|c|c|c|}
\hline Characteristic & $\begin{array}{l}\text { Neoadjuvant } \\
(n=61)\end{array}$ & Adjuvant $(n=58)$ \\
\hline \multicolumn{3}{|l|}{ Age (years) } \\
\hline Median & 62 & 68 \\
\hline Range & $35-84$ & $35-88$ \\
\hline $\begin{array}{l}\text { Gender (male: } \\
\text { female) }\end{array}$ & $1.44: 1$ & $1.52: 1$ \\
\hline \multicolumn{3}{|l|}{ Stage } \\
\hline $\mathrm{I}$ & 2 & 2 \\
\hline II & 23 & 19 \\
\hline III & 35 & 37 \\
\hline IV & 1 & 0 \\
\hline \multicolumn{3}{|l|}{ Radiation dose } \\
\hline $25 \mathrm{~Gy} / 5$ fractions & 4 & 0 \\
\hline $\begin{array}{l}45 \mathrm{~Gy} / 25 \\
\text { fractions }\end{array}$ & 3 & 6 \\
\hline $\begin{array}{l}50.4 \mathrm{~Gy} / 28 \\
\text { fractions }\end{array}$ & 52 & 41 \\
\hline $\begin{array}{l}54 \mathrm{~Gy} / 30 \\
\text { fractions }\end{array}$ & 0 & 4 \\
\hline Unfinished & 2 & 7 \\
\hline $\begin{array}{l}\text { Concomitant } \\
\text { Chemo }\end{array}$ & 55 & 51 \\
\hline
\end{tabular}

\begin{tabular}{|l|l|l|l|}
\hline Factors & Male $(\mathbf{n}=\mathbf{7 1}$ & \multicolumn{1}{|c|}{$\begin{array}{c}\text { Female } \\
(\mathbf{( n = 4 8}\end{array}$} & P Value \\
\hline $\begin{array}{l}\text { Small bowel } \\
\text { (volume }(\mathrm{ml}\end{array}$ & 213 & 335 & 0.0015 \\
\hline $\begin{array}{l}\text { Bladder } \\
\text { (volume }(\mathrm{ml}\end{array}$ & $(\mathrm{n}=60) 191$ & $(\mathrm{n}=43) 171$ & 0.63 \\
\hline (\%) Diarrhea & & & \\
\hline Grade 1 & 27 & 15 & 0.89 \\
\hline Grade 2 & 7 & 5 & \\
\hline Grade 3 & 4 & 3 & \\
\hline Grade 4 & 6 & 2 & \\
\hline $\begin{array}{l}\text { Small bowel } \\
\text { (volume }(\mathrm{ml}\end{array}$ & & & \\
\hline At RT dose & & & 0.0045 \\
\hline V5 Gy & 197 & 321 & 0.0012 \\
\hline V 10 Gy & 165 & 310 & 0.0011 \\
\hline V 15 Gy & 117 & 229 & 0.0014 \\
\hline V 20 Gy & 87 & 185 & 0.0011 \\
\hline V 25 Gy & 69 & 161 & 0.0005 \\
\hline V 30 Gy & 51 & 141 & 0.0004 \\
\hline V35 Gy & 45 & 131 & 0.0006 \\
\hline V 40 Gy & 40 & 121 & 0.0023 \\
\hline V 45 Gy & 23 & 64 & \\
\hline
\end{tabular}

Table 3: Small bowel volume in patients of different gender. Abbreviation: RT= Radiotherapy

Table 1: Clinical and tumor characteristics for all patients $(\mathrm{n}=119)$.

\begin{tabular}{|l|l|l|l|}
\hline \multicolumn{5}{|c|}{ Factors } & $\begin{array}{l}\text { Neoa j u va n t } \\
(\mathbf{n = 6 1})\end{array}$ & $\begin{array}{l}\text { A d j u v a n t } \\
(\mathbf{n = 5 8})\end{array}$ & P Value \\
\hline $\begin{array}{l}\text { Small bowel } \\
\text { volume (ml) }\end{array}$ & 197 & 325 & 0.0033 \\
\hline $\begin{array}{l}\text { B 1 a d d e r } \\
\text { volume (ml) }\end{array}$ & $219(\mathrm{n}=54)$ & $171(\mathrm{n}=49)$ & 0.68 \\
\hline Diarrhea (\%) & & & \\
\hline Grade 1 & 19 & 23 & 0.34 \\
\hline Grade 2 & 6 & 6 & \\
\hline Grade 3 & 2 & 5 & \\
\hline Grade 4 & 6 & 2 & \\
\hline $\begin{array}{l}\text { Small bowel } \\
\text { volume (ml) }\end{array}$ & & & \\
\hline At RT dose & & & 0.0016 \\
\hline V5 Gy & 185 & 325 & 0.0008 \\
\hline V10 Gy & 161 & 301 & 0.0018 \\
\hline V15 Gy & 112 & 192 & 0.0016 \\
\hline V20 Gy & 73 & 160 & 0.0009 \\
\hline V25 Gy & 63 & 140 & 0.0002 \\
\hline V30 Gy & 48 & 118 & 0.0002 \\
\hline V35 Gy & 37 & 107 & $<0.0001$ \\
\hline V40 Gy & 33 & 98 & $<0.0001$ \\
\hline V45 Gy & 20 & 66 & \\
\hline
\end{tabular}

\begin{tabular}{||l|l|l|}
\hline Factors & Slope & P Value \\
\hline (Age $($ years & $(\mathrm{ml}) 2.81$ & 0.032 \\
\hline (BMI $(\mathrm{Kg} / \mathrm{m} 2$ & $(\mathrm{ml}) 0-3.1$ & 0.2400 \\
\hline (Bladder volume $(\mathrm{ml}$ & $(\mathrm{ml})-0.31$ & 0.0015 \\
\hline $\begin{array}{l}\text { Female }(1) \text { vs. Male } \\
((0\end{array}$ & $(\mathrm{ml}) 94$ & 0.0019 \\
\hline $\begin{array}{l}\text { Neo-adjuvant }(1) \text { vs. } \\
\text { (adjuvant }(0\end{array}$ & $(\mathrm{ml})-93$ & 0.0017 \\
\hline
\end{tabular}

Table 4: Single predictors for small bowel volume in the pelvis of patients with rectal Cancer

Abbreviation: $\mathrm{RT}=$ Radiotherapy

Table 2: Clinical and relevant dosimetric results for all patients $(\mathrm{n}=119$, median value).

Abbreviation: RT= Radiotherapy 
Citation: Liu J (2017) The Factors Affecting Small Bowel Volume in the Pelvis of Patients Receiving Radiotherapy for Rectal Cancer. J Clin Case Rep Case Stud 2017: 1-5.

\begin{tabular}{||l|l|l|}
\hline Patient group & (PTV 45 Gy (ml & P Value \\
\hline Neoajuvant & 1492 & \\
\hline Adjuvant & 1466 & 0.4400 \\
\hline Male & 1469 & \\
\hline Female & 1494 & 0.5600 \\
\hline
\end{tabular}

Table 6: PTV 45 Gy in different group of patients with rectal cancer (median $\mathrm{ml})$.

\section{Discussion}

Our data clearly shows that small bowel volumes in the pelvis are affected by different factors including pelvic surgery, gender, bladder volume, and patient age [13]. The volumes in the pelvis are increased when RT is given after definitive surgery in patients with rectal cancer. Pelvic surgery with abdominoperineal resection in particular causes small bowel shifts down into the pelvis (personal observation). This might be one of the reasons for the increased bowel toxicities of patients receiving post-surgery RT, as reported previously [5]. Our current study did not observe a statistically significant increase of acute bowel toxicities in patients who received adjuvant chemoradiotherapy as compared to those patients who received neoadjuvant treatment. This might be due to the sample size of this cohort was not large enough to see the clinical difference

It is commonly acknowledged that there is a direct connection between the irradiated small bowel volumes and the severity of treatment related diarrhea [14]. Our finding of the increased small bowel volume in the radiation fields in the specified conditions may draw attention to avoid such conditions or to use technical such as Intensity Modulated Radiotherapy (IMRT) or Rapid Arc to avoid or reduce small bowel volumes being irradiated.

The small bowel has been estimated to have a 5\% risk of late toxicity at 5 years with doses between $45-50$ Gy $[15,16]$. Previous studies showed a relationship between small bowel dose-volume and the development of acute diarrhea in patients receiving pelvic irradiation $[16,17]$. The alternative explanation for our data not showing statistically significant differences in incidence of acute diarrhea to correlate with the increased small bowel volume in the irradiation fields might be due to the dominating effects of the concomitant chemotherapy 5-FU which affects the entire GI system and its effects shadowed the role played by the small bowel volume in the radiation fields. It would be interesting to see if there is a correlation between the irradiated small bowel volume and the incidence of long term small bowel toxicities such as bowel stenosis and obstruction in our patients since it has been suggested that the absolute volume of small bowel irradiated to 45 Gy or higher is associated with an increased risk of late GI toxicity $[18,19]$.

We report that adjuvant RT, female gender, smaller bladder volume, and older age are predictors of the increased small bowel volumes being irradiated. This gives concrete anatomic evidence to prove the superiority of neoadjuvant RT over adjuvant RT especially for female or older patients.

The German trial showed that neo-adjuvant chemoradiotherapy not only increased local control but also decreased GI toxicities [5]. The mechanism for this was not fully explored. It is highly likely that less small bowel volumes being irradiated in the neoadjuvant setting, as demonstrated in our study, might be part of the explanations for the decreased GI toxicities.

The increased small bowel volume in the pelvis of female patients and post-surgery patients in our study is not related to a larger PTV volume.

Although there are large number of confounding variables for diarrhea in patients with rectal cancer, confirmation of the existence of a relationship between the irradiated small bowel volume and the incidence of acute diarrhea or late bowel toxicities is important. Through radiotherapy technical improvements, such as IMRT, small bowel dose volume may be reduced [20-23].

\section{Conclusion}

The results of our study demonstrate that factors such as pelvic surgery, being female, flat bladder, and older age are associated with increased small bowel volumes in pelvis. These would increase the irradiated small volumes in patients receiving radiotherapy for rectal cancer. Therefore, giving radiotherapy before the surgery or using technical such as IMRT or Rapid Arc to avoid or reduce the small bowel volumes being irradiated is warranted.

\section{References}

1. Cammà C, Giunta M, Fiorica F, Pagliaro L, Craxi A, et al. (2000) Preoperative radiotherapy for resectable rectal cancer. A metaanalysis. JAMA 284: 1008-1015.

2. Swedish Rectal Cancer Trial, Cedermark B, Dahlberg M, Glimelius B, Påhlman L (1997) Improved survival with preoperative radiotherapy in resectable rectal cancer. $\mathrm{N}$ Engl J Med 336: 980-987.

3. Gastrointestinal Tumor Study Group (1985) Prolongation of the disease-free interval in surgically treated rectal carcinoma. $\mathrm{N}$ Engl J Med 312: 1465-1472.

4. O'Connell MJ, Martenson JA, Wieand HS, Krook JE, Macdonald JS, et al. (1994) Improving adjuvant therapy for rectal cancer by combining protracted-infusion fluorouracil with radiation therapy after curative surger. N Engl J Med 331: 502-507.

5. Sauer R, Becker H, Hohenberger W, Rödel C, Wittekind C, et al. (2004) Preoperative versus postoperative chemoradiotherapy for rectal cancer. N Engl J Med 351: 1731-1740.

6. Tepper JE, O'Connell MJ, Petroni GR, Hollis D, Cooke E, et al. (1997) Adjuvant postoperative fluorouracil-modulated chemotherapy combined with pelvic radiation therapy for rectal cancer: initial results of Inter-group 0114. J Clin Oncol 15: 20302039.

7. Miller RC, Sargent DJ, Martenson JA, Macdonald JS, Haller D, et al. (2002) Acute diarrhea during adjuvant therapy for rectal 
Citation: Liu J (2017) The Factors Affecting Small Bowel Volume in the Pelvis of Patients Receiving Radiotherapy for Rectal Cancer. J Clin Case Rep Case Stud 2017: 1-5.

cancer: A detailed analysis from a randomized intergroup trial. Int J Radiat Oncol Biol Phys 54: 409-413.

8. John M, Flam M, Palma N (1996) Ten-year results of chemoradiation for anal cancer: Focus on late morbidity. Int $\mathrm{J}$ Radiat Oncol Biol Phys 34: 65-69.

9. Tanum G. Tveit K, Karlsen KO, Hauer-Jensen M (1991) Chemotherapy and radiation therapy for anal carcinoma: Survival and late morbidity. Cancer 67: 2462-2466.

10. Cummings BJ, Keane TJ, O'Sullivan B, Wong CS, Catton CN (1991) Epidermoid anal cancer: treatment by radiation alone or by radiation and 5 -fluorouracil with and without mitomycin $\mathrm{C}$. Int J Radiat Oncol Biol Phys 21: 1115-1125.

11. Hu K, Minsky BD, Cohen AM, Kelsen DP, Guillem JG, et al. (1999) 30 Gy may be adequate dose in patients with anal cancer treated with excisional biopsy followed by combined-modality therapy. J Surg Oncol 70: 71-77.

12. Acute Radiation Morbidity Scoring Criteria. RTOG.

13. Liu J, Liu H, Mou B, Nugent Z, Demers A (2010) The determinants of small bowel volume in pelvis of patients receiving radiotherapy for rectal cancer: A multivariate analysis. Int J Radiat Oncol Biol Phys 78: 325-326.

14. Reis T, Khazzaka E, Welzel G, Wenz F, Hofheinz RD, et al. (2015) Acute small-bowel toxicity during neoadjuvant combined radiochemotherapy in locally advanced rectal cancer: determination of optimal dose-volume cut-off value predicting grade 2-3 diarrhea. Radiat Oncol 10: 30.

15. Emami B, Lyman J, Brown A, Coia L, Goitein M, et al. (1991) Tolerance of normal tissue to therapeutic irradiation. Int J Radiat Oncol Biol Phys 21: 109-122.

16. Mak AC, Rich TA, Schultheiss TE, Kavanagh B, Ota DM, et al.
(1994) Late complications of postoperative radiation therapy for cancer of the rectum and rectosigmoid. Int J Radiat Oncol Biol Phys 28: 597-603.

17. Robertson JM, Lockman D, Yan D, Wallace M (2008) The dosevolume relationship of small bowel irradiation and acute grade 3 diarrhea during chemoradiotherapy for rectal cancer. Int J Radiat oncol Biol Phys 70: 413-418.

18. Tho LM, Glegg M, Paterson J, Yap C, MacLeod A, et al. (2006) Acute small bowel toxicity and preoperative chemoradiotherapy for rectal cancer: investigating dose-volume relationships and role for inverse planning. Int J Radiat oncol Biol Phys 66: 505513.

19. Gallagher MJ, Brereton HD, Rostock RA, Zero JM, Zekoski DA, et al. (1986) A prospective study of treatment techniques to minimize the volume of pelvic small bowel with reduction of acute and late effects associated with pelvic irradiation. Int J Radiat Oncol Biol Phys 12: 1565-1573.

20. Kavanagh BD, Pan CC, Dawson LA, Das SK, Li XA, et al. (2010) Radiation dose-volume effects in the stomach and small bowel. Int J Radiat Oncol Biol Phys 76: 101-107.

21. Roeske JC, Bonta D, Mell LK, Lujan AE, Mundt AJ (2003) A dosimetric analysis of acute gastrointestinal toxicity in women receiving intensity modulated whole-pelvic radiation therapy. Radiother Oncol 69: 201-207.

22. Jabbour SK, Patel S, Herman JM, Wild A, Nagda SN, et al. (2012) Intensity-modulated radiation therapy for rectal carcinoma can reduce treatment breaks and emergency department visits. Int J of Surg Oncol 2012: 891067.

23. Samuelian JM, Callister MD, Ashman JB, Young-Fadok TM, Borad MJ, et al. (2012) Reduced acute bowel toxicity in patients treated with intensity-modulated radiotherapy for rectal cancer. Int J radiat Oncol Biol Phys 82: 1981-1987. 